\title{
AVALIAÇÃO DO DESEMPENHO FUNCIONAL DE UM PAVIMENTO URBANO: ESTUDO DE CASO
}

\author{
COSTA, AIRLES DUARTE \\ Graduanda em Engenharia Civil \\ IFAL- Campus Palmeira dos Índios \\ Alagoas; Brasil \\ airlescosta@hotmail.com
}

\author{
SOUSA, ERICA LOPES \\ Graduanda em Engenharia Civil \\ IFAL - Campus Palmeira dos Índios \\ Alagoas; Brasil \\ ericas_lopes@hotmail.com
}

\author{
PINTO, ISABELLY CHRISTINY MONTEIRO DE SOUZA \\ Docente \\ IFAL- Campus Palmeira dos Índios \\ Alagoas; Brasil \\ isabellycmsp@gmail.com
}

\section{RESUMO}

Para uma melhor qualidade de vida dos usuários, as vias dos centros urbanos necessitam estar em boas condições de tráfego. Visando comprovar tal afirmação, buscou-se analisar a qualidade da pavimentação em paralelepípedo, no Conjunto Edval Vieira Gaia, na cidade de Palmeira dos Índios-AL. Esse trabalho tem como objetivo fazer uma análise das principais patologias existentes na pavimentação local e uma avaliação da percepção dos moradores com relação a tal problema, a fim de facilitar a compreensão do estado atual da pavimentação. Utilizou-se uma metodologia baseada em uma avaliação objetiva e subjetiva. Na primeira, foram levantados os tipos de patologias existentes nas vias, através de inspeção visual, com o caminhamento da seção, utilizando como instrumento auxiliar de noção das dimensões dos defeitos encontrados uma régua de duas cores (branca e amarela). Os registros fotográficos também foram importantes nesse estudo. Através deles, conseguiu-se expor as patologias e enfatizar a importância de uma boa execução dos serviços, manutenção e reparos. Já na avaliação subjetiva, utilizou-se da aplicação de um questionário aos seus usuários. As principais patologias encontradas com seus respectivos percentuais foram: panela (13,92\%), peças salientes $(13,92 \%)$ e ondulação $(12,66 \%)$. Pôde-se chegar à conclusão de que as ruas principais são as que apresentam um maior número de defeitos, causando grande desconforto a população, além de gerar prejuízos financeiros aos proprietários dos veículos. Palavras-chave: pavimento, paralelepípedo, patologias.

\begin{abstract}
For a better quality of life for users, roads in urban centers need to be in good traffic conditions. In order to prove this statement, we sought to analyze the quality of the cobblestone paving at the Conjunto Edval Vieira Gaia, in the city of Palmeira dos Índios-AL. This work aims to make an analysis of the main pathologies existing in the local paving and an assessment of the residents' perception regarding this problem, in order to facilitate the understanding of the current state of the paving. A methodology based on an objective and subjective evaluation was used. In the objective evaluation, the types of pathologies existing on the roads were surveyed, through visual inspection, with the walking of the section, using a two-color ruler (white and yellow) as an auxiliary instrument for noting the dimensions of the defects found. Photographic records were also important in this study. Through them, it was possible to expose the pathologies and emphasize the importance of a good execution of services, maintenance and repairs. In the subjective evaluation, a questionnaire was used to its users. The main pathologies found with their respective percentages were: holes (13.92\%), protruding parts (13.92\%) and wavy sections $(12.66 \%)$. It was possible to conclude that the main streets are the ones with the greatest number of defects, causing great discomfort to the population, in addition to generating financial losses for vehicle owners.
\end{abstract}

Keywords: pavement, parallelepiped, pathologies. 


\section{INTRODUÇÃO}

Os registros de estradas e pavimentação de ruas existem desde tempos bastante remotos, nos quais, os povos existentes necessitavam fazer ligação entre terras conquistadas e facilitar o comércio. Os sistemas construtivos eram baseados em pedras irregulares ou aparelhadas e apresentavam grande durabilidade devido ao superdimensionamento.

Anos mais tarde, com a evolução industrial e o crescimento populacional surgiram as grandes fábricas e delas vieram os veículos, necessitando assim, de um maior investimento na ligação entre cidades e no setor da pavimentação.

Devido ao crescimento populacional surgiu também o crescimento dos centros urbanos e com isso, a busca por uma melhor qualidade de vida, que está diretamente relacionada aos serviços públicos de infraestrutura que incluem a pavimentação e drenagem das vias.

Para Bernucci et al. (2006), pavimento é uma estrutura de múltiplas camadas de espessuras finitas, construída sobre a superfície final de terraplenagem, destinada técnica e economicamente a resistir aos esforços oriundos do tráfego de veículos e do clima, e a propiciar aos usuários melhoria nas condições de rolamento, com conforto, economia e segurança.

Atualmente, existe a preferência pelo pavimento asfáltico e o pavimento rígido para pavimentações em relação à pavimentação em paralelepípedo, visto que, esta exige mais do trabalhador e oferece um acabamento mais grosseiro, embora, ainda seja bastante empregada em pequenas cidades e vias locais.

No entanto, a ausência de recursos, fiscalização dos serviços, mão de obra qualificada e fiscalização da carga que por ali passa, acabada causando um reflexo negativo na qualidade das vias, independentemente do tipo de pavimento utilizado, através do surgimento de desgastes como os buracos que provocam diversos transtornos como a vibração excessiva, danos aos veículos e desconforto aos usuários.

De acordo com o IBGE 2010, Palmeira dos Índios possui cerca de 7,2\% de domicílios urbanos em vias públicas com urbanização adequada (presença de bueiro, calçada, pavimentação e meio-fio). Diante disso, esse estudo busca analisar a qualidade da pavimentação desenvolvida em paralelepípedo, no Conjunto Residencial Edval Vieira Gaia, localizado na BR 316, tendo seu acesso principal, e uma saída para a AL 115, na cidade de Palmeira dos Índios, Alagoas.

O Conjunto Residencial Edval Vieira Gaia, foi entregue aos beneficiados pelo programa governamental Minha Casa Minha Vida em 20/04/2012, contando com 451 unidades residenciais e possui toda a infraestrutura de um conjunto planejado, entretanto, passados apenas sete anos a pavimentação já apresenta diversas patologias. Desse modo, o objetivo deste artigo é fazer uma análise das principais patologias da pavimentação do conjunto e uma avaliação da percepção dos moradores com relação a tal problema.

\section{REFERENCIAL TEÓRICO}

\subsection{Generalidades}

Pavimento é uma estrutura construída após a terraplenagem, destinada a resistir e distribuir ao subleito os esforços verticais oriundos dos veículos, a melhorar as condições de rolamento quanto ao conforto e segurança e a resistir aos esforços horizontais, tornando mais durável a superfície de rolamento (DNER-700-GTTR, 1997). Já o Manual de Pavimentação (DNIT,2006), descreve o pavimento como uma estrutura de camadas em que matérias de diferentes resistências e deformabilidade são colocadas em contato resultando, um elevado grau de complexidade, que resiste as deformações e tensões atuantes.

Segundo Júnior (1992), os pavimentos de vias públicas são constituídos por estruturas que apresentam diversas camadas com espessuras específicas e executadas após a terraplenagem. As estruturas e o revestimento têm como finalidade resistir aos esforços (verticais, horizontais e tangenciais) decorrentes do tráfego de veículos e dos efeitos das intempéries, além de proporcionar aos usuários conforto, segurança e economia. 
Esses pavimentos, de acordo com o Manual de Pavimentação (DNIT,2006) são classificados em flexível, semi-rígido e rígido. O flexível, objeto de estudo deste trabalho, consiste naquele em que todas as camadas sofrem deformação elástica significativa sob o carregamento aplicado e, portanto, a carga se distribui em parcelas aproximadamente equivalentes entre camadas. O semi-rígido é caracterizado por possuir uma base cimentada por algum aglutinante com propriedades cimentícias, por exemplo, por uma camada de solo cimento revestida por uma camada asfáltica. E, o rígido é aquele em que o revestimento tem uma elevada rigidez em relação às camadas inferiores e, portanto, absorve praticamente todas as tensões provenientes do carregamento aplicado.

\subsection{Tipos de pavimentação}

Diante dos inúmeros tipos de pavimentação, faz-se necessário avaliar o custo-benefício, a mão de obra local disponível, além das características como o tipo de tráfego, se é leve ou pesado, rápido ou lento, de grande ou pequena movimentação, entre outros. Entre os mais usuais tem-se a pavimentação asfaltica; com pedra irregular e paralelepipedo; e bloco intertravado de concreto.

\section{- Asfáltica}

O revestimento asfáltico é a camada superior e tem como funções: resistir diretamente às ações do tráfego e transmiti- las de forma atenuada às camadas inferiores, impermeabilizar o pavimento, além de melhorar as condições de rolamento (conforto e segurança). A constituição do revestimento asfáltico é feita por associação de agregados e de materiais asfálticos, podendo ser de duas maneiras principais: por mistura ou por penetração (BERNUCCI et al., 2008).

- Pedra irregular e paralelepípedo

"Os paralelepípedos, representam um revestimento de extraordinária durabilidade, podendo, inclusive, ser reaproveitados com mudança da face exposta ao rolamento. Pode-se definir paralelepípedo como uma peça de pedra paralela com a forma do sólido que lhe empresta o nome. Revestimento de paralelepípedos é a camada dessas pedras assentadas sobre base de areia, rejuntadas de preferência com material betuminoso - asfalto de alta resistência à penetração." (SENÇO, 2008).

Já o revestimento de pedras irregulares, assentadas lado a lado sobre uma base de solo escolhido, formando um autêntico mosaico. $\mathrm{O}$ assentamento é iniciado com as pedras-guias, que dão, em intervalos prefixados, o nivelamento do pavimento (SENÇO, 2008). São muito similares os dois tipos de pavimentos, pois utilizam-se da mesma matéria prima, e do mesmo método construtivo, o que difere de um e outro é o acabamento da pedra.

- Bloco intertravado de concreto

A NBR 15953 (ABNT,2011), define o pavimento intertravado como um pavimento flexível, que apresenta uma estrutura composta por uma camada base, seguida por uma camada de revestimento de blocos de concretos, sobrepostas a uma camada de assentamento. As juntas entre as peças são preenchidas por material de rejunte e o intertravamento do sistema é proporcionado pela contenção.

\subsection{Principais defeitos dos revestimentos com paralelepípedos}

Para Senço (2001), os pavimentos em paralelepípedos superam os demais quanto à durabilidade, mesmo sob as condições mais rudes e intensas de tráfego. Segundo o DNIT (2006), a utilização desse tipo de pavimento se restringe a pátios de estacionamento, vias urbanas e alguns acessos viários, pois sua aplicação em rodovias caiu consideravelmente, devido a intensificação da utilização de pavimentos asfálticos e de concreto.

Considerando que o tema analisado neste trabalho é avaliação de pavimentos urbanos com revestimento de paralelepípedos, vale salientar que os principais defeitos destes pavimentos são demonstrados na Tabela 1. 
Tabela 1 - Defeitos dos pavimentos com revestimento de paralelepípedos

\begin{tabular}{|c|c|}
\hline Remendos & $\begin{array}{l}\text { Remendo de conservação padrão - Consiste na reparação de um defeito existente anteriormente, } \\
\text { com a remoção e reposição do revestimento original. } \\
\text { Remendo regular com mistura asfáltica - Compreende a reparação de um defeito existente } \\
\text { anteriormente, executado utilizando-se mistura asfáltica, normalmente apresentando forma de } \\
\text { quadrilátero bem definido. } \\
\text { Remendo de conservação emergencial - Definido como a reparação de um defeito existente } \\
\text { anteriormente, executado sem cuidados técnicos, algumas vezes com materiais inadequados, } \\
\text { possuindo formato irregular. }\end{array}$ \\
\hline Juntas & Constitui-se na falta de material de preenchimento das juntas entre as peças do revestimento. \\
\hline Afundamentos & $\begin{array}{l}\text { Afundamento com solevamento lateral - Caracterizado pela formação de depressões nas vias } \\
\text { acompanhadas de deslocamentos laterais ou elevações das áreas adjacentes. } \\
\text { Afundamento sem solevamento lateral - Possui as mesmas características do afundamento } \\
\text { descrito anteriormente, exceto os deslocamentos laterais ou elevações adjacentes. } \\
\text { Afundamento das trilhas de roda com ou sem solevamento lateral - Apresenta afundamentos } \\
\text { generalizados nas regiões de caminho preferencial dos pneus dos veículos conhecidas como } \\
\text { trilhas de roda acompanhado de um dos afundamentos citados anteriormente. }\end{array}$ \\
\hline Ondulação & $\begin{array}{l}\text { Ocorre através da formação de ondas perpendiculares ao eixo da via, resultando em vibrações } \\
\text { excessivas dos veículos em movimento. }\end{array}$ \\
\hline Elevação & $\begin{array}{l}\text { Irregularidade causada pela elevação da superfície em relação ao nível original do pavimento. } \\
\text { Compreende as elevações oriundas do crescimento de raízes de árvores existentes sob as camadas } \\
\text { do pavimento e as elevações causadas pelos remendos mal executados. }\end{array}$ \\
\hline Desnível & $\begin{array}{l}\text { trata-se do desnível observado junto às tampas dos poços de visita das redes das redes } \\
\text { subterrâneas em relação ao revestimento ou devido a ausência desta. }\end{array}$ \\
\hline $\begin{array}{l}\text { Derrame de } \\
\text { material }\end{array}$ & $\begin{array}{l}\text { Ocorrência de despejo de material asfáltico ou cimentício solidificado sobre o revestimento, } \\
\text { gerando irregularidades na superfície. }\end{array}$ \\
\hline Panelas & $\begin{array}{l}\text { Ocasionadas pela ausência de peças do calçamento e exposição das camadas inferiores. } \\
\text { Apresenta estado avançado de defeito quando há falta de mais de cinco peças adjacentes }\end{array}$ \\
\hline Deformação & $\begin{array}{l}\text { Abrange as deformações longitudinais, transversais ou radiais, descaracterizando a disposição } \\
\text { das peças. Muito comum em ladeiras, curvas, interseções e paradas de ônibus, devido a } \\
\text { frenagem, aceleração e mudança de direção dos veículos. }\end{array}$ \\
\hline
\end{tabular}

Fonte: Danieleski (2004) adaptado pelas autoras.

\section{METODOLOGIA}

A metodologia empregada para realização do presente estudo se baseou em duas componentes: a avaliação objetiva e a avaliação subjetiva.

\subsection{Avaliação objetiva}

O levantamento foi efetuado nas principais vias do conjunto Edval Vieira Gaia, localizado em Palmeira dos Índios - AL. Os defeitos foram levantados em cada via e realizados por dois avaliadores através de inspeção visual, com o caminhamento da seção, utilizando como instrumento auxiliar de noção das dimensões dos defeitos encontrados uma régua de duas cores (branca e amarela). A mesma possui $15 \mathrm{~cm}$ de largura e $140 \mathrm{~cm}$ de comprimento divididos em 10 faixas de $14 \mathrm{~cm}$, pintadas alternadamente. Anotou-se os tipos de defeitos existentes na tentativa de classificá-los conforme a Tabela 1.

\subsection{Avaliação subjetiva}

Esta avaliação concentrou-se na aplicação de um questionário voltado para os usuários frequentes das vias, no qual se coletou dados acerca da percepção e do nível de satisfação aliado ao conforto durante a utilização das faixas. Tal questionário foi composto de questões abertas e fechadas, sendo aplicado pelos autores na população residente do conjunto. O questionário foi composto pelas seguintes questões: "qual tipo de veículo passa por essa via?"; "Como você 
classifica as ruas desse conjunto quanto ao conforto ao dirigir?"; "Você já presenciou algum reparo sendo executado nessas vias?',

\section{RESULTADOS E DISCUSSÃO}

O conjunto Edval Vieira Gaia possui um total de 13 ruas, sem nomenclaturas, sendo adotadas as quadras e lotes como forma de localização das unidades residenciais, podendo ser acessado por duas estradas: a BR-316 e a AL-115. Para facilitar esse estudo numerou-se as vias como mostrado na figura 1.

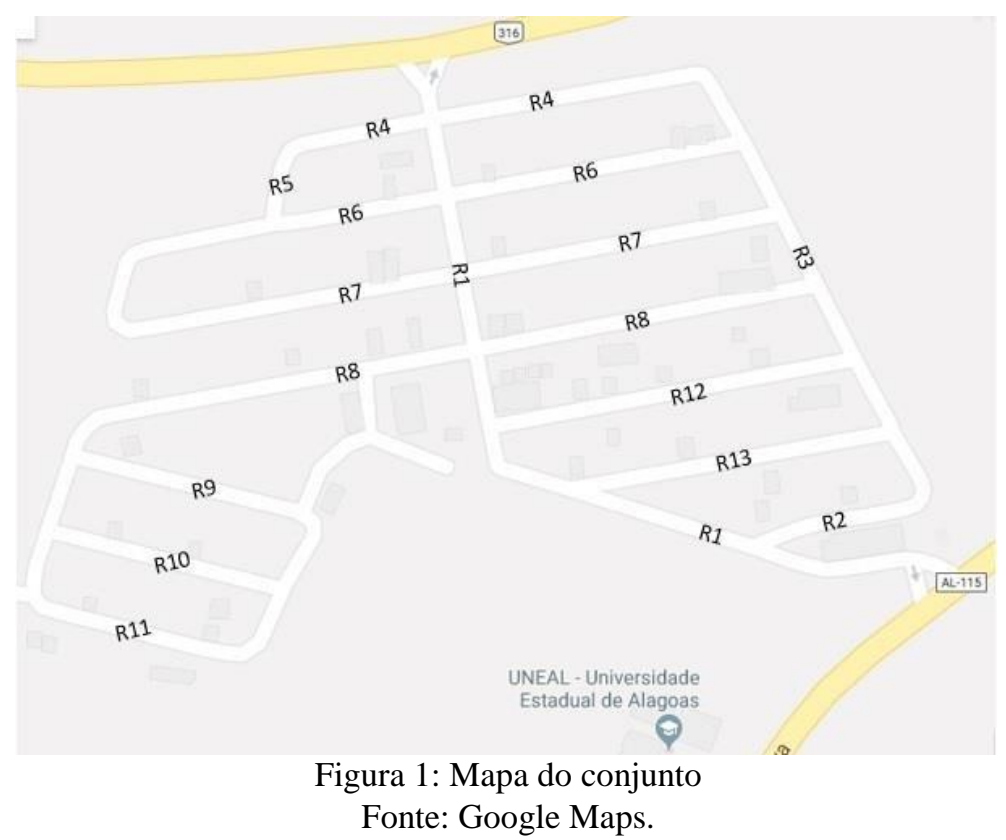

A avaliação objetiva teve como base os registros das patologias existentes. Percebeu-se que todas as ruas do conjunto apresentaram patologias, sendo que as mais graves e em maior quantidade concentraram-se em algumas vias principais. Com base na Tabela 2, os autores elencaram os defeitos encontrados de acordo com o código atribuído, conforme exposto abaixo.

Tabela 2 - Classificação das patologias encontradas nas vias em estudo.

\begin{tabular}{|l|l|l|}
\hline Cód. & \multicolumn{1}{|c|}{ Tipo de Defeito } & \multicolumn{1}{|c|}{ Vias que apresentaram a patologia } \\
\hline PL 02 & Remendo de intervenções em rede subterrânea & \\
\hline PL 03 & Remendo de conservação emergencial & R1; R8; R12; R13 \\
\hline PL 04 & Remendo regular com mistura asfáltica & \\
\hline PL 05 & Peças trincadas ou quebradas & R9; R10; R12 \\
\hline PL 06 & Peças com desgaste ou polidas & R2; R6 \\
\hline PL 07 & Peças salientes & R1; R2; R3; R4; R5; R6; R7; R8; R10; R11; R13 \\
\hline PL 08 & Juntas sem preenchimento & \\
\hline PL 09 & Panela & R1; R2; R3; R4; R6; R7; R8; R9 R10; R12; R13 \\
\hline PL 10 & Afundamento com solevamento lateral & R1; R4; R7; R8; R9; R12; R13 \\
\hline PL 11 & Afundamento sem solevamento lateral & R1; R2; R6; R7; R8 \\
\hline PL 12 & Afundamento nas trilhas de roda com solevamento lateral & R1; R6; R7; R9; R10; R12; R13 \\
\hline PL 13 & Afundamento nas trilhas de roda sem solevamento lateral & R2; R4; R8 \\
\hline PL 14 & Ondulação & R1; R2; R3; R6; R7; R8; R9; R10; R11; R12 \\
\hline PL 15 & $\begin{array}{l}\text { Deformação por aceleração, frenagem ou mudança de } \\
\text { direção. }\end{array}$ & R1 \\
\hline
\end{tabular}




\section{CBPAT 2020

\begin{tabular}{|l|l|l|} 
PL 16 & Elevação & \\
\hline PL 17 & Desnível, quebra ou falta de tampa de PV & R1; R3; R4; R6; R7; R8; R11 \\
\hline PL 18 & Imperfeição em suporte de concretos de tampa de PV & R1; R3; R4; R6; R7; R8; R11; R12 \\
\hline PL 19 & Derrame de material & \\
\hline
\end{tabular}

Fonte: Autoral.

A partir dos dados acima, optou-se pela apresentação dos dados em formato de gráfico, de forma a facilitar a interpretação dos resultados, disposto abaixo.

Gráfico 2: Patologias encontradas nas vias em estudo.

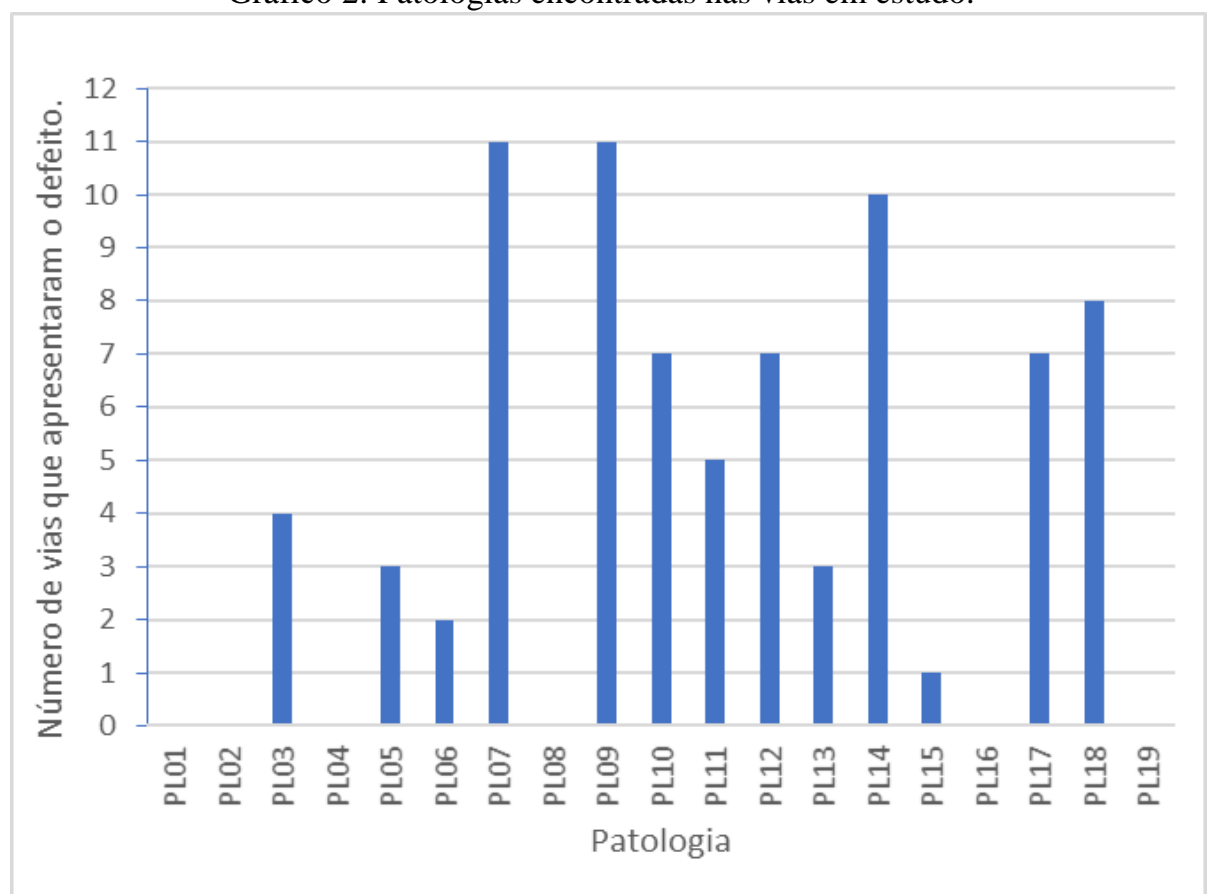

Fonte: Autoral.

Os defeitos PL07 - Peças Salientes e o PL09 - Panela, foram os mais encontrados durante o estudo. Os registros fotográficos também foram importantes nesse estudo. Através deles, conseguiu-se expor os defeitos e enfatizar a importância de uma boa execução dos serviços, manutenção e reparos.

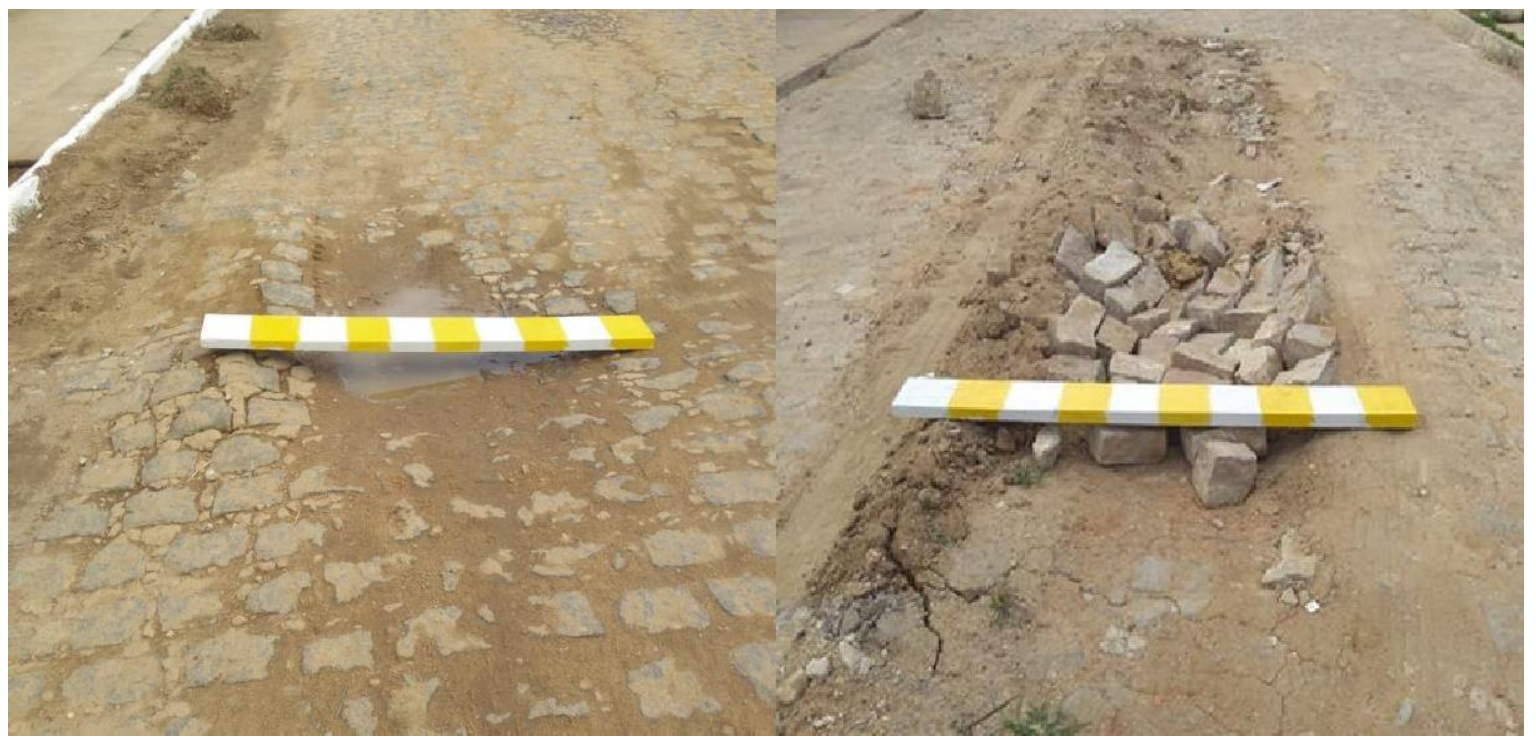

Figura 2: a) Afundamento com solevamento lateral. b) Afundamento sem solevamento lateral.

Fonte: Autoral. 

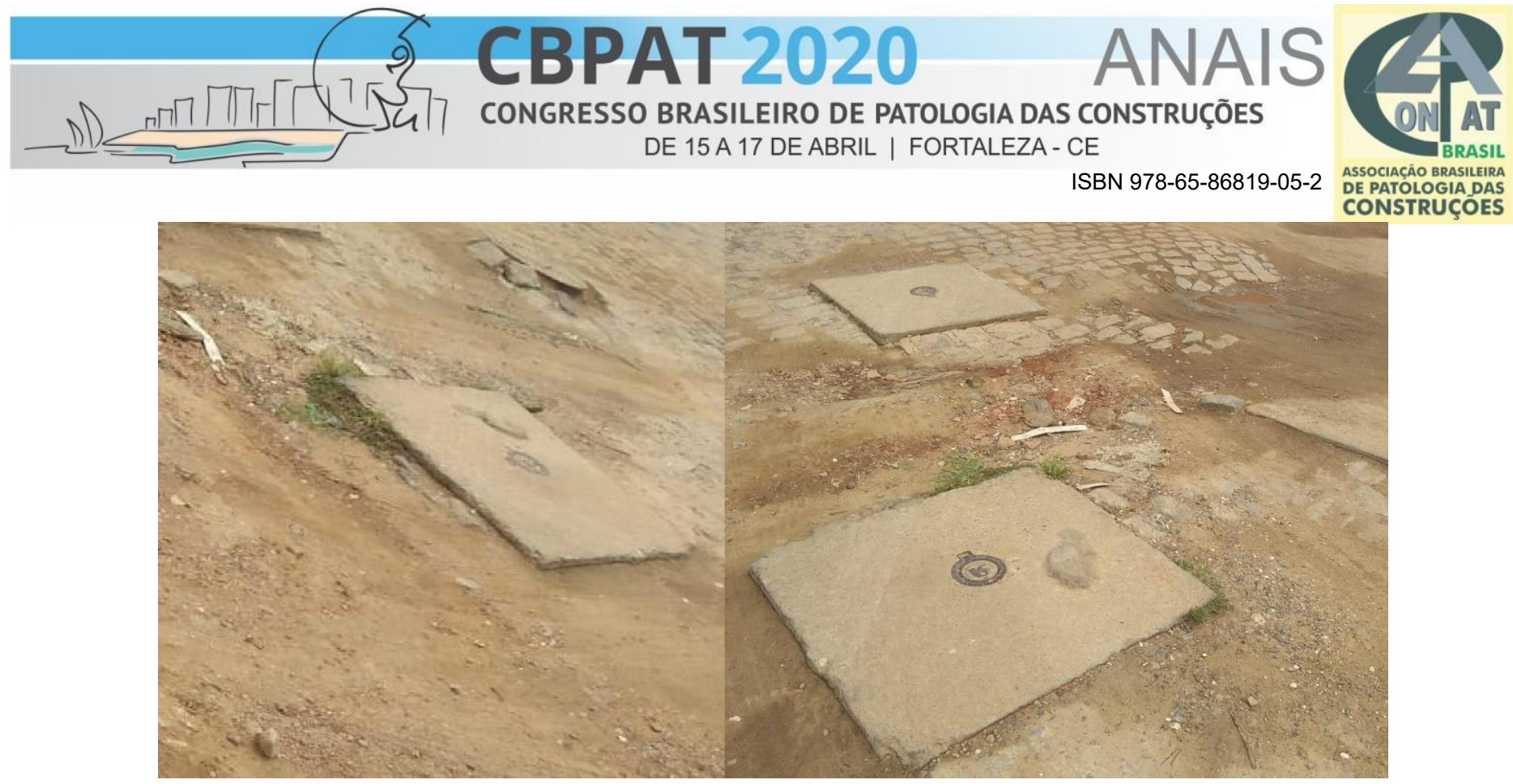

Figura 3: a) e b) Desnível e imperfeição em suporte de concretos de tampas de PV (Poço de visita).

Fonte: Autoral.

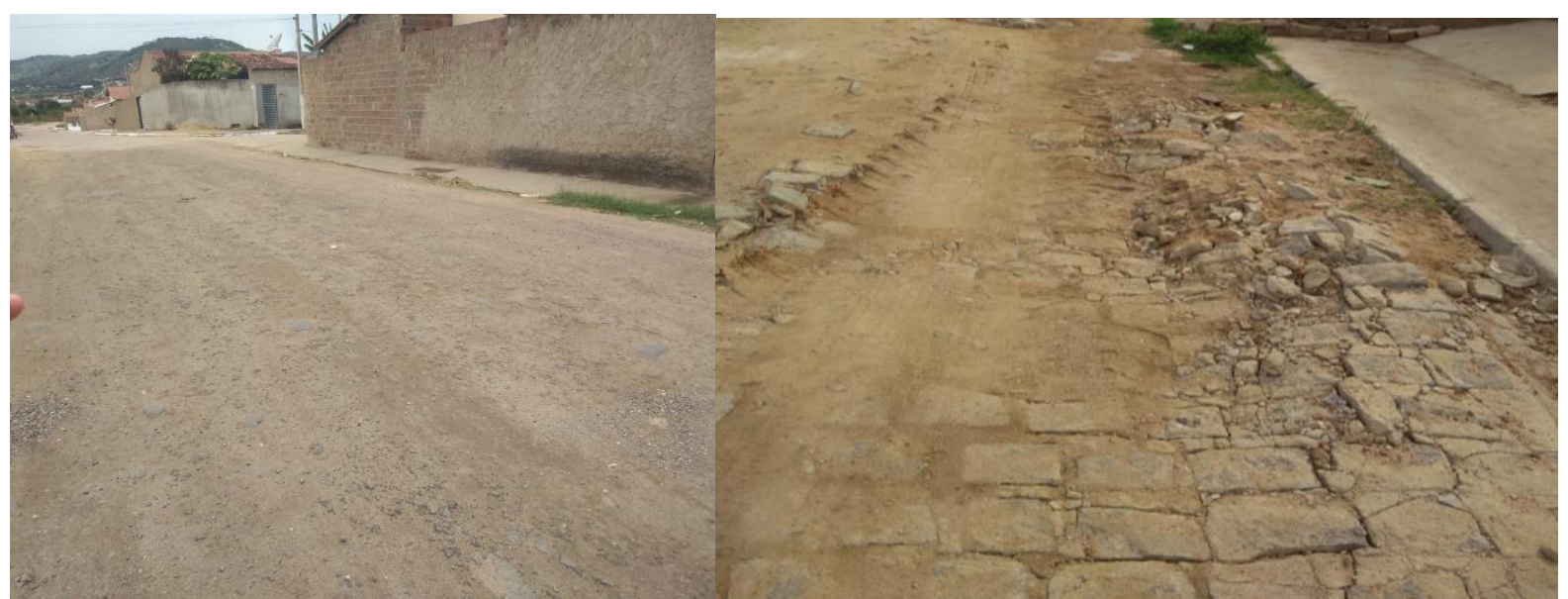

Figura 4: a) Remendo emergencial em parte da via. b) Afundamento nas trilhas de roda com solevamento lateral, peças quebradas e peças salientes.

Fonte: Autoral.

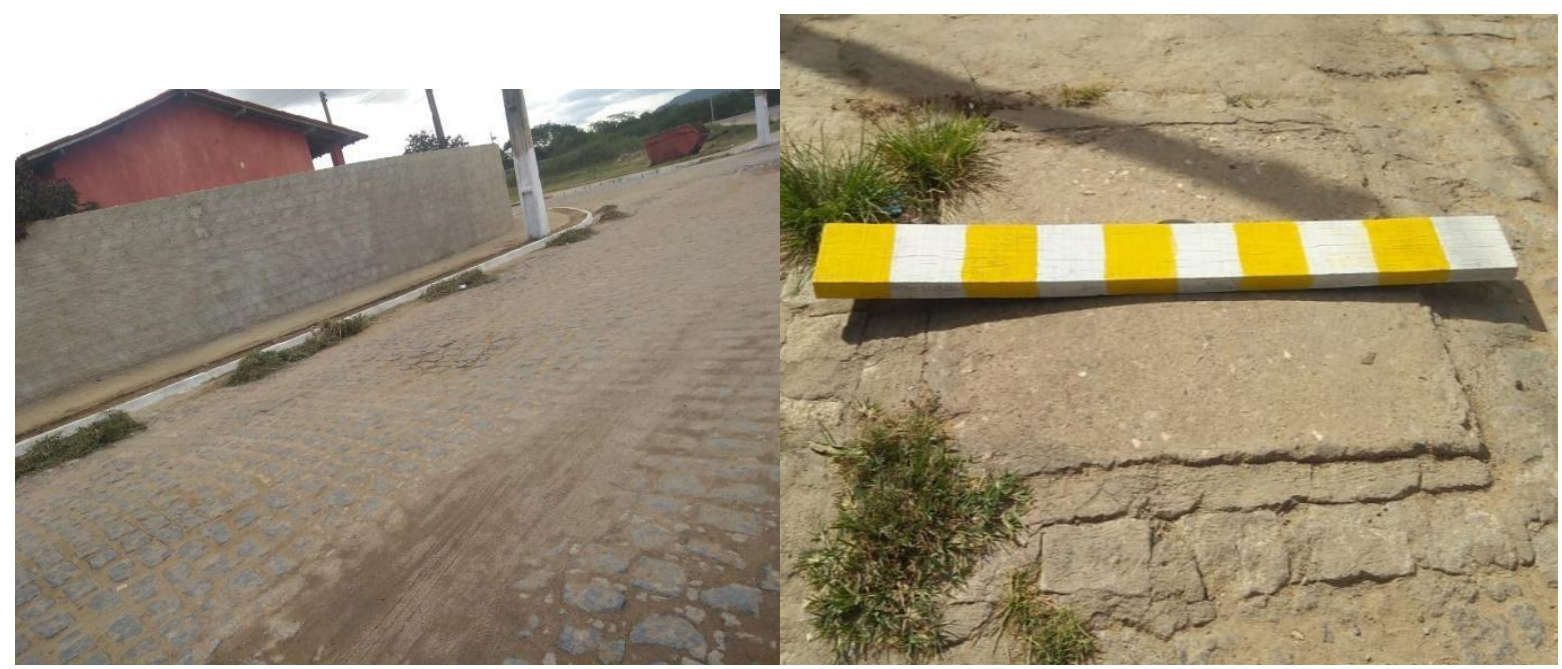

Figura 5: a) Ondulação, deformação por aceleração, frenagem ou mudança de direção. b) Desnível e imperfeição em suporte de concretos de tampas de PV.

Fonte: Autoral. 


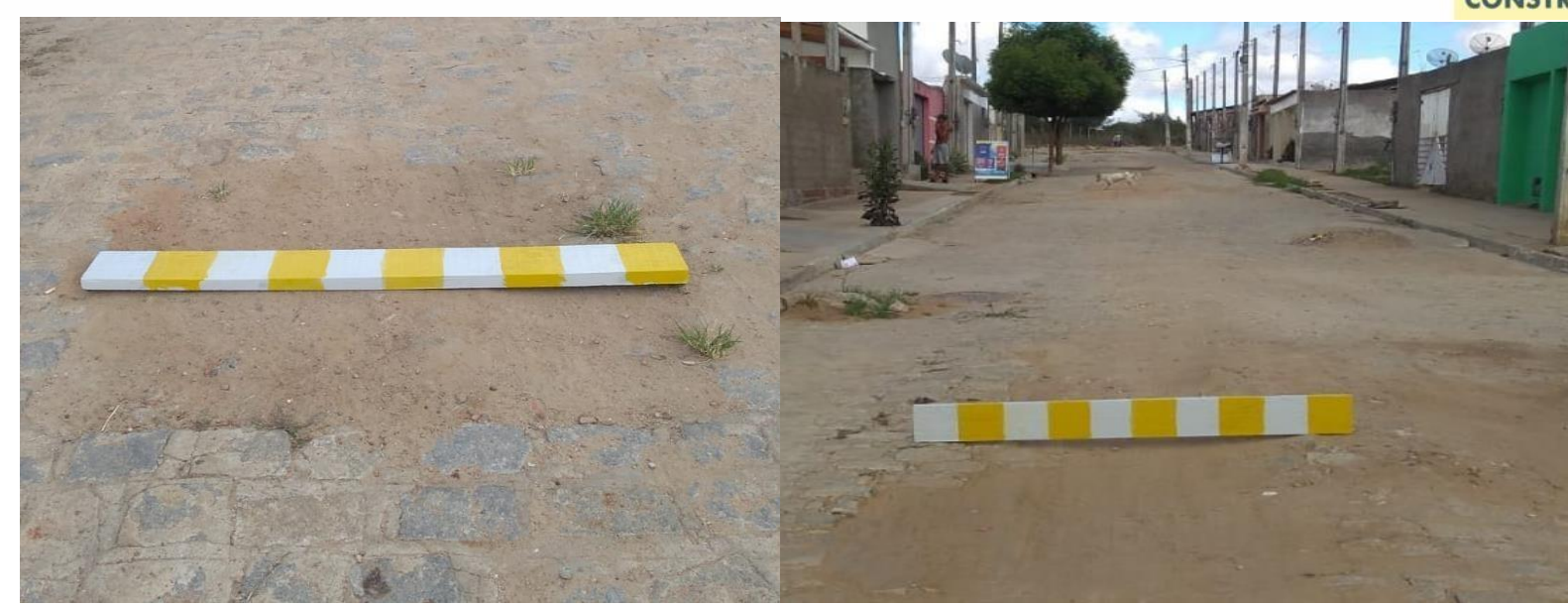

Figura 6: a) Panela e b) Remendo emergencial e afundamento.

Fonte: Autoral.

Com relação à avaliação subjetiva, foi realizada a aplicação do questionário aos usuários. Em virtude do péssimo estado de conservação das ruas, as respostas foram praticamente unânimes, ocorrendo pequenas variações. Baseado no Anexo I obteve-se os resultados abaixo:

Foi confirmado que trafegam na via, que deveria ser local, todo tipo de veículo, ou seja: carro de passeio, van de transporte de passageiros intermunicipais, ônibus escolar, caminhões com as mais variadas cargas e motocicletas.

- Quanto ao conforto das ruas do conjunto, ao utilizá-las motorizado, foram consideradas por $90 \%$ dos entrevistados como péssimas e $10 \%$ como regulares.

- Diante dos relatos, pode-se perceber que o serviço do calçamento foi mal feito, não levando em consideração que anteriormente à construção do Conjunto, o terreno possuía áreas alagadas e por isso, deveria ter sido feita uma regularização mais resistente e compacta, evitando assim, o aparecimento precoce dos buracos. A causa dos buracos também pode estar relacionada com à passagem excessiva de veículos pesados que utilizam as vias do Conjunto como atalho, gerando uma sobrecarga na pavimentação. Percebeu-se ainda, através das entrevistas, que a drenagem de águas pluvias ocorre de forma ineficiente, sendo relatado pelos moradores que no período chuvoso as bocas de lobo ficam transbordando e não conseguem comportar toda água escoada. Desse modo, torna-se mais um agravante para os danos no pavimento.

- Quanto aos reparos, todos os entrevistados alegaram já ter presenciado anteriormente, entretanto, apenas de caráter emergencial e que não foram bem executados, fazendo com que o problema se torne recorrente.

- Para resolver as patologias existentes tem-se como possiveis soluções:

a) Refazer todo o calçamento de maneira mais adequada, utilizando materiais de melhor qualidade;

b) Implantar uma fiscalização quanto à entrada dos veículos pesados;

c) Realizar manutenção mais eficiente quanto aos reparos do calçamento e ao sistema pluvial.

\section{CONCLUSÕES}

Com base no desenvolvimento deste trabalho, verificou-se que após sete anos da entrega do Conjunto, todas as ruas que o compõe apresentam patologias, sendo que as mais frequentes foram: peças salientes, panela e ondulação. Pôde-se chegar à conclusão de que as ruas principais são as que apresentam um maior número de defeitos, causando grande desconforto aos seus usuários além de gerar prejuízos financeiros aos proprietários de veículos.

Através da aplicação do questionário aos usuários das vias, constatou-se que no Conjunto ocorre o trânsito de todos os tipos de veículos, citados anteriormente no corpo deste trabalho, confirmando-se que as ruas em sua maioria são de péssima qualidade com relação ao conforto dos usuários e que a causa principal é a presença de peças salientes e buracos (panelas).

Os entrevistados se mostraram cientes das péssimas condições do pavimento, tendo-se como possíveis causas dos defeitos encontrados a má execução da pavimentação com paralelepípedos, a passagem excessiva de veículos pesados e a uma drenagem insuficiente. 
Observou-se durante a construção da metodologia desse trabalho, uma escassez de informações que auxiliassem no estudo de pavimentos com paralelepípedo, sendo este de grande importância por estar presente em uma significativa parcela da malha viária, principalmente de caráter urbano.

Como sugestões de estudos futuros têm-se a análise do grau das patologias encontradas e um estudo do solo do conjunto a fim de caracterizar melhor a situação encontrada.

\section{REFERÊNCIAS BIBLIOGRÁFICAS}

ABNT - ASSOCIAÇÃO BRASILEIRA DE NORMAS TÉCNICAS. NBR 15953: Pavimento intertravado com peças de concreto - Execução. Rio de Janeiro, 2011.

BERNUCCI, Liedi Bariani. et al. Pavimentação asfáltica: formação básica para engenheiros. 1 ed. Rio de Janeiro: Petrobras: ABEDA, 2008.

DANIELESKI, Maria Luiza. Proposta de Metodologia Para Avaliação Superficial de Pavimentos Urbanos: Aplicação à Rede Viária de Porto Alegre. Porto Alegre: Dissertação de Mestrado. Universidade Federal do Rio Grande do Sul, 2004.

DNER-700. Glossário de Termos Técnicos Rodoviários. Rio de Janeiro1997.

DNIT - Departamento Nacional de Infra-Estrutura de Transportes. Manual de Pavimentação. $3^{\text {a }}$ ed. Rio de Janeiro, 2006.

INSTITUTO BRASILEIRO DE GEOGRAFIA E ESTATÍSTICA (IBGE) - Território e meio ambiente. 2010.

Disponível em: < https://cidades.ibge.gov.br/brasil/al/palmeira-dos-indios/panorama> Acesso em 04 abr. de 2019.

JÚNIOR, Fernando Augusto. Manual de Pavimentação Urbana. São Paulo: Instituto de Pesquisas Tecnológicas (IPT), 1992.

JUNIOR, Ivan José Ary. Pavimento Intertravado como Ferramenta de Moderação do Tráfego nos Centros Comerciais de Travessias Urbanas - Estudo de Caso Guaiúba, CE. 2007. 221f. Tese (Mestrado em Engenharia de Transportes) - Universidade Federal do Ceará, Fortaleza.

MEDINA, Jacques de. Mecânica dos pavimentos. Rio de Janeiro: Editora UFRJ, 1977.

SENÇO, Wlastermiler de. Manual de Técnicas de Pavimentação. Vol 1, 2a ed. São Paulo: Editora Pini Ltda, 2008.

SENÇO, Wlastermiler de. Manual de Técnicas de Pavimentação. Vol 2, 1ª ed. São Paulo: Pini, 2001. 